\title{
Complex Regional Pain Syndrome II
}

National Cancer Institute

\section{Source}

National Cancer Institute. Complex Regional Pain Syndrome II. NCI Thesaurus. Code C121572.

A neurologic condition characterized by burning pain, tenderness, swelling, and changes in the skin color and temperature of a body part or extremity associated with demonstrable nerve injury. This form is less frequent in pediatric patients. 